\title{
Do Millennials care about NPOs? Intergenerational differences in attitudes towards nonprofit organizations
}

\author{
Marko Kovic ${ }^{* b}$ and Nina Hänsli ${ }^{\dagger a}$ \\ ${ }^{\mathrm{a}}$ Walker Management AG, Sursee, Switzerland. \\ bars cognitionis GmbH, Zurich, Switzerland.
}

July 2018

\begin{abstract}
In this study, we analyze whether there are differences in attitudes towards nonprofit organizations (NPOs) between the generational cohorts of Baby Boomers, Generation X, and Millennials. We do so by analyzing survey data from Switzerland in two steps, a Bayesian estimation as well as a cluster analysis. The overall results suggest that there are, at best, only few and small intergenerational differences: The only consistent effect we find are the more negative attitudes of the Baby Boomer cohort towards professional associations and towards sports NPOs, but those differences could be due to life cycle rather than intergenerational effects. Overall, our results suggest that the Millennial generational cohort is at least as interested in and willing to engage with NPOs as previous generational cohorts.
\end{abstract}

*marko.kovic@ars-cognitionis.ch

†nina.haensli@wamag.ch 


\section{Introduction: Millennials and nonprofit orga- nizations}

The antecedents and predictors of attitudes towards nonprofit organizations (NPOs) are the subject of rich and ongoing research. Factors such as gender, income, education, religiosity, political attitudes, and even personality traits have been found to correlate with and influence attitudes towards NPOs to some degree. In recent years, an additional explanatory factor for attitudes towards NPOs has been proposed: Intergenerational differences. More specifically, a number of both practice-oriented (Feldmann et al. 2015; Saratovsky, Feldmann, and Case 2013; Feldmann 2016) as well as academic works and studies (Nisbett and Strzelecka 2017; Gorczyca and Hartman 2017; Smith, Cohen, and Pickett 2014) have suggested that the so-called Millennial generation in Western countries, the cohort born roughly between 1982 and 2002 (Howe and Strauss 2009), is different enough from previous generations with regards to their attitudes towards NPOs that they warrant closer practical as well as scientific scrutiny.

Describing and analyzing the peculiarities, potentials, and pitfalls of Millennials' attitudes towards NPOs presupposes that the Millennial generation is indeed different from other generations in terms of attitudes towards NPOs. That presupposition, however, has not directly been tested yet. The existing works about the Millennial generational cohort's attitudes towards NPOs single out that generational cohort in their analyses, without direct comparisons to previous generational cohorts. The goal of the present study is to address this research gap by means of a direct intergenerational comparison. More specifically, we aim to answer the following research question: Are there intergenerational differences in attitudes towards NPOs?

In order to answer this research question, we first describe some theoretical considerations. Then we proceed to describe our research design that revolves around a survey conducted in Switzerland. That section is followed by a presentation of the data analysis results. Finally, we discuss the results and address both the limitations of our study as well as its tentative practical implications. 


\section{The idea of generations}

\subsection{Intergenerational differences as a macro-level ap- proach}

The genesis of attitudes towards NPOs is the topic of ongoing and varied research that can be categorized according to the level of analysis that is being applied: Micro-level, meso-level, or macro-level.

The micro-level strand of the existing research is focused on antecedents and predictors of individual attitudes. This line of research has demonstrated that there is no single micro-level factor that fully explains attitudes towards nonprofit organizations, but that different factors can have an impact. For example, religiosity (Becker and Dhingra 2001; Helms and Thornton 2012), age (J. Wilson 2012; Bekkers and Wiepking 2011), greater income (Wiepking and Bekkers 2012), higher levels of education (J. Wilson 2012; Einolf and Yung 2018), some personality traits (agreeableness and extraversion) (Bekkers 2010), gender (Piper and Schnepf 2007), political attitudes (Brooks and J. Q. Wilson 2007; Margolis and Sances 2017), and the level of social capital (Brown and Ferris 2007; Wang and Graddy 2008) can affect volunteering and donation behavior.

A second strand of research is focused on meso-level factors. Whereas micro-level research aims to explain attitudes in terms of individual traits and characteristics, meso-level research is aimed at the traits and activities of NPOs themselves. To that end, meso-level research commonly addresses different dimensions of management and performance, such as the problem of general effectiveness in goal attainment (Lecy, Schmitz, and Swedlund 2012), the adoption of business-like tactics and strategies (Balabanis, Stables, and Phillips 1997; Maier, Meyer, and Steinbereithner 2016), the impact of organizational strategy on survival prospects (Mendoza-Abarca and Gras 2017), or impact and effectiveness of marketing activities (Dolnicar and Lazarevski 2009, Helmig, Jegers, and Lapsley 2004). Even though meso-level research does not always directly address the question of attitudes towards NPOs within the general population, this strand of research does provide valuable insights into why and how the activities and characteristics of NPOs matter for being successful and thus in resonating with the general public or with more specific audiences and stakeholders.

A third strand of research is focused on macro-level factors. The goal of such a perspective is to understand and model generalized dynamics of the third sector from the point of view of the whole system. This is often performed within the theoretical rationale of economic models, whereby some functions of demand by the general population or by specific sub-groups in 
the general population and supply by NPOs is hypothesized and analyzed (Westall 2009, Rose-Ackerman 1996, Steinberg 2003, Gui 1991). A theoretical macro-level approach related to traditional economic analysis, population ecology (Hannan and J. Freeman 1977), tries to understand survival and failure of populations of organizations not as a dynamic process of demand and supply, but rather as a quasi-evolutionary process of selection: Organizations that fit better to their changing environment have better chances of surviving. Population ecology has been proposed as a promising macro-level framework for the study of success and failure of NPOs (Kramer 2000). The empirical application of the population ecology approach in the study of NPOs can take the form of survival analysis, whereby factors that contribute to the survival of NPOs can be identified (Hager, Galaskiewicz, and Larson 2004).

The notion that intergenerational differences might play a role in shaping attitudes towards NPOs is also a macro-level conceptual thought, since the factors that potentially lead to intergenerational differences are broad macrolevel factors and trends.

\subsection{Generations as a sociological concept}

The concept of generations has a biological connotation, but it is a sociological rather than biological concept. From a sociological point of view, generations can be understood as cohorts of people who have been born and socialized into similar socio-historic circumstances and who share a similar set of values and attitudes because of that common experience (Mannheim 1952 Lambert 1972). One of the research areas that provides strong evidence for the existence of generations in this sociological sense is the research on values and intergenerational value change. Values are the generalized internal moral compass that guides the formation of more specific contextual attitudes (Hitlin and Piliavin 2004). Values have been shown to be relatively stable over the course of a lifetime, and they are formed in large part during childhood and adolescence, contingent on socio-economic circumstances (Inglehart and Welzel 2010; Welzel and Inglehart 2010; Norris and Inglehart 2011).

The concept of a Millennial generation as the generation that has emerged after the Generation X and Baby boomer generations is not a stringent sociological concept, but, originally, rather a practice-oriented popular one. The authors who have created the concept of the Millennial generation, Howe and Strauss 2009, base that concept on a mix of sociological reasoning and popular storytelling. Even though the concept of a the Millennial generation is not the result of rigorous theoretical and empirical work, it enjoys widespread popularity in public discourse as well in scientific research. Some research areas in which the concept of Millennials features prominently is information seeking 
and communication behavior (Tkalac Verčič and Verčič 2013; Anderson and Rainie 2012; Bolton et al. 2013), consumer behavior (Katherine Taken Smith 2012 A. M. Young and Hinesly 2012), or workplace preferences and behavior (Twenge and Campbell 2012; Ng, Schweitzer, and Lyons 2010 Deal, Altman, and Rogelberg 2010).

A general theme in Millennials-related research, both as a premise and as a conclusion, is the idea that members of the Millennial generational cohort seem to value self-actualization and individuality higher than previous generations (Taylor et al.2014). That assumption is not altogether implausible. In the sociological account of intergenerational value change, values are understood as being heavily shaped by the materialistic realities experienced during childhood and adolescence. In a quasi-Maslowian sense (Maslow 1943), the theory goes, people will value higher-order needs such as selfactualization more if lower-order needs were fully met during their childhood and adolescence. Given that the Millennial generational cohort is arguably a generation that has been socialized into conditions suitable to higher-order needs (decrease of conflict in the post-Cold War era, high and rising living standards, increased access to education), the Millennial generational concept does have both theoretical and real-world plausibility.

\subsection{The conceptual challenge of the Millennial genera- tional account}

Even though the Millennial concept of intergenerational differences is plausible and popular, the concept is not without problems. One such challenge is the specific operationalization of the Millennial, the Generation X, and the Baby Boomer generations in the existing research. Somewhat surprisingly, there is no agreement on when each of those generations begin and end (Parry and Urwin 2011). Most operationalizations roughly, but imprecisely follow the definition proposed by Howe and Strauss 2009, whereby the Baby Boomer generation is the cohort born between 1943 and 1960, Generation X that born between 1961 an 1981, and the Millennial generation that born between 1982 and 2002 (the post-Millennial generation is sometimes referred to as Generation Z (Turner 2015; Seemiller and Grace 2016)). The imprecision in the existing operationalizations of the Millennial and the related generational cohorts indirectly points at a weakness of the Millennial account. If the Millennial concept is mainly used in a practice-oriented manner as a heuristic, then the scientific and popular interest is not so much the concept and its merits in and of themselves, but mostly the explanatory power of the concept. In other words: If the concept of the Millennial (in combination with the 
Generation X and Baby Boomer) generational cohort is casually regarded as a true premise, then any and all results will tend to simply to further confirm that premise - to the detriment of the concept itself.

Addressing this challenge is not easy, because it is somewhat of a conceptual chicken-or-egg situation; exploring latent intergenerational differences without an analysis of explicit attitudes is difficult. There are, however, steps that can be taken to address the problem. A first step is to not rely a priori on an analysis of one and only one generational cohort. For example, if an analysis is performed only on members of the Millennial generational cohort, then any and all results can only serve as confirmation of the Millennial concept. If, on the other hand, different generational cohorts are compared to each other, the results will inevitably allow for a more precise estimation of the explanatory power of the Millennial generational concept. A potential second step is methodological triangulation: If different methods are applied to the empirical study of Millenial-related phenomena, the results might offer a more complete picture than results obtained only from a singular methodological approach. Of course, methodological triangulation should be justified and limited in order to avoid the problem of (inadvertently) exploiting researcher degrees of freedom (Simmons, Nelson, and Simonsohn 2011; Gelman and Loken 2013).

In this study, we implement both of these steps, direct intergenerational comparison as well as methodological triangulation, into our research design and data analysis strategy.

\section{Design, data and methods}

\subsection{Design}

In order to answer the research question, we conducted an online survey among residents of the German- and French-speaking parts of Switzerland. The survey was fielded in February 2017 through a general population online panel curated by a market research firm (Innofact AG), and 735 participants have participated in the survey. Surveys that rely on online panels apply so-called non-probability sampling (Callegaro et al. 2014), meaning that not every member of the target population has an equal probability of being included in the survey sample. A consequence of nonprobability sampling is that one cannot calculate survey variance (popularly referred to as "margin of error"). However, through a Bayesian approximation, it is possible to estimate so-called Bayesian credible intervals for online panel-based surveys (Roshwalb, El-Dash, and C. Young 2016). The credible interval for the survey used in 
this study is $3.7 \%$.

An important aspect of non-probability samples is the question of survey weights. For this survey, we have not applied weighting adjustments such as post-stratification or raking (Zhang 2000) after the data collection. Instead, the data collection itself was conducted according to the demographic weighting criteria of language region, age, and gender. As a result, $75 \%$ of the survey respondents reside in the German-speaking part of Switzerland, and the other $25 \%$ in the French-speaking part; $49.9 \%$ of respondents are women; and the mean and median ages of all respondents are 43.8 and 45, respectively. These distributions closely resemble the overall proportions within the Swiss population (Kucera and Krummenacher 2017).

A cross-sectional survey design has obvious limitations. The goal of this paper is to explore potential intergenerational differences, and a longitudinal panel-based design would be ideally suited to this task. When we use a cross-sectional sample rather than a longitudinal one, we potentially risk confounding life cycle effects or even pure randomness as intergenerational differences. We take this limitation into account in the discussion of the results.

\subsection{Data}

In order to receive a detailed picture of attitudes towards NPOs, we implemented two attitudinal dimensions in the survey: We asked the study participants about different aspects of attitudes towards different kinds of NPOs.

We have operationalized the first of these two dimensions, the different aspects attitudes towards NPOs, with five survey items as summarized in Table 1.

The first item is general interest in different kinds of NPOs. With the next three items, we measure how likely the participants are to engage in specific actions: Joining an NPO as a member, donating money to an NPO, and volunteering for an NPO. With the final item, we measure how interested the study participants are to work professionally for an NPO. Volunteering, donating, and becoming a member are traditional activities associated with the nonprofit sector (Tchirhart 2006; R. B. Freeman 1997; Lee and Chang 2007; García-Mainar and Marcuello 2007). Professional, paid work is increasingly relevant in the nonprofit sector as well, because working for NPOs has become a viable career choice (Leete 2006; Onyx and Maclean 1996).

We have operationalized the second attitudinal dimension, the different kinds of NPOs, as six NPO types: Professional associations, charities, religious organizations, political organizations, cultural organizations, and sports 
Table 1: Operationalization of the attitude dimension.

\begin{tabular}{lll}
\hline Item & Question & Item scale \\
\hline General interest & $\begin{array}{l}\text { How interested are you, generally, in the following } \\
\text { types of NPOs? }\end{array}$ & $1-10$ \\
Membership & $\begin{array}{l}\text { How likely are you to join one of the follow- } 1-10 \\
\text { ing types of NPOs as a member in the next 12 }\end{array}$ \\
& $\begin{array}{l}\text { months? } \\
\text { How likely are you to donate to one of the fol- } 1-10 \\
\text { lowing types of NPOs in the next 12 months? }\end{array}$ \\
Volunteering & $\begin{array}{l}\text { How likely are you to volunteer for one of the } 1-10 \\
\text { following types of NPOs in the next 12 months? }\end{array}$ \\
Professional work & $\begin{array}{l}\text { How much would you like to work professionally } \\
\text { for one of the following types of NPOs? }\end{array}$ \\
\hline
\end{tabular}

organizations. This typology is a simplification of the typology proposed in the International Classification of Non-profit Organizations (ICNPO) (Lester M. Salamon and Helmut K. Anheier 1997; Lester M Salamon and Helmut K Anheier 1996). We have opted for a simplified typology for two reasons. First, the full ICNPO typology is simply far too complex to be meaningfully applied in a survey. Second, our simplification aims to employ a most different systems logic (Teune and Przeworski 1970): Our goal was to include such types of NPOs that are clearly distinct from one another, so that the cognitive load on survey participants is minimized.

Overall, the survey participants answered five attitudinal questions for six types of NPOs. This results in thirty separate measures of different kinds of attitudes towards different kinds of NPOs. These thirty measures are the empirical basis of the present study. Descriptive information of the data set is summarized in subsection A.1 in the appendix.

\subsection{Method 1: Estimation of group means}

The first part of our data analysis consists of comparing the participant responses for the generational cohorts of Baby Boomers (born between 1943 and 1960), Generation X (born between 1961 and 1981), and Millennials (born between 1982 and 2002). This is the operationalization applied by Howe and Strauss 2009. Following this operationalization, we have excluded two survey participants born after 2002, resulting in a total sample size of 733 people.

In order to estimate the mean responses for each generational cohort 
for each question, we estimated a simple linear Bayesian regression model (Gelman, Carlin, et al. 2013) of the following form:

$$
\begin{gathered}
y \sim \mathcal{N}(\mu, \sigma) \\
\mu=\alpha+\beta x \\
\alpha \sim \mathcal{N}(0,4.5) \\
\beta \sim \mathcal{N}(0,4.5) \\
\sigma \sim \operatorname{Cauchy}(0,2.5)
\end{gathered}
$$

The above model is fairly simple: We use a normal distribution as the sampling distribution (noise distribution), and very broad, noncommittal priors both for the intercept $\alpha$ and the coefficients $\beta$. The prior for the standard deviation $\sigma$ is also vague, a half-Cauchy distribution trunkated at zero (Polson and Scott 2012). All in all, this model puts great emphasis on the data and hardly any on the priors. The benefit of a Bayesian estimation is that the results are probability distributions rather than singular point estimates. Probabilistic estimates can be interpreted intuitively, not least because they are a direct quantification of uncertainty.

We have performed the model estimation with the package brms (Bürkner 2017) that interfaces with the probabilistic language Stan (Carpenter et al. 2017) within the computational environment $\mathrm{R}$ ( $\mathrm{R}$ Core Team 2015). We have estimated all 30 models (five attitudinal questions for six NPO types) with 1000 warmup and 1000 sampling iterations for four separate sampling chains. The sampling chains for all models converged sucessfully, as indicated by the potential scale reduction factor (Gelman and Rubin 1992) of 1.0 for all estimates of all models.

The results of the model estimations are presented in graphical form in section 4 by comparing the full posterior distributions of the estimates.

\subsection{Method 2: Cluster analysis}

The second, complementary part of our data analysis consists of analyzing potential differences between generational cohorts, but without an a priori specification of cohorts. We did this by conducting a series of cluster analyses. The basic idea of cluster analysis is to group data in such a way that data points within groups are more similar to each other than data points between groups (Anderberg 2014). We opted for a specific variant of cluster analysis: Gaussian mixture modeling in combination with the expectation-maximization algorithm (C. Fraley and Raftery 1998). This approach has the benefit of 
minimizing the necessary a priori input. We did not specify beforehand how many and what kinds of clusters we were expecting. Instead, the best cluster solutions were chosen by comparing model fit according to the Schwarz criterion (Schwarz 1978) (sometimes referred to as the Bayesian Information Criterion).

We performed the cluster analysis with the package mclust (Chris Fraley et al. 2017) within the computational environment $R$ ( $R$ Core Team 2015). As in the first methodolocial step, we conducted 30 analyses in total (five attitudinal questions for six NPO types). We discuss the cluster analysis results in section 4, the graphical summaries of the cluster analyses are presented in subsection A.2 in the appendix.

\section{Results}

\subsection{General interest}

The estimation results for general interest in NPOs are summarized in Figure 1.

Figure 1: Estimation results for general interest in different types of NPOs.

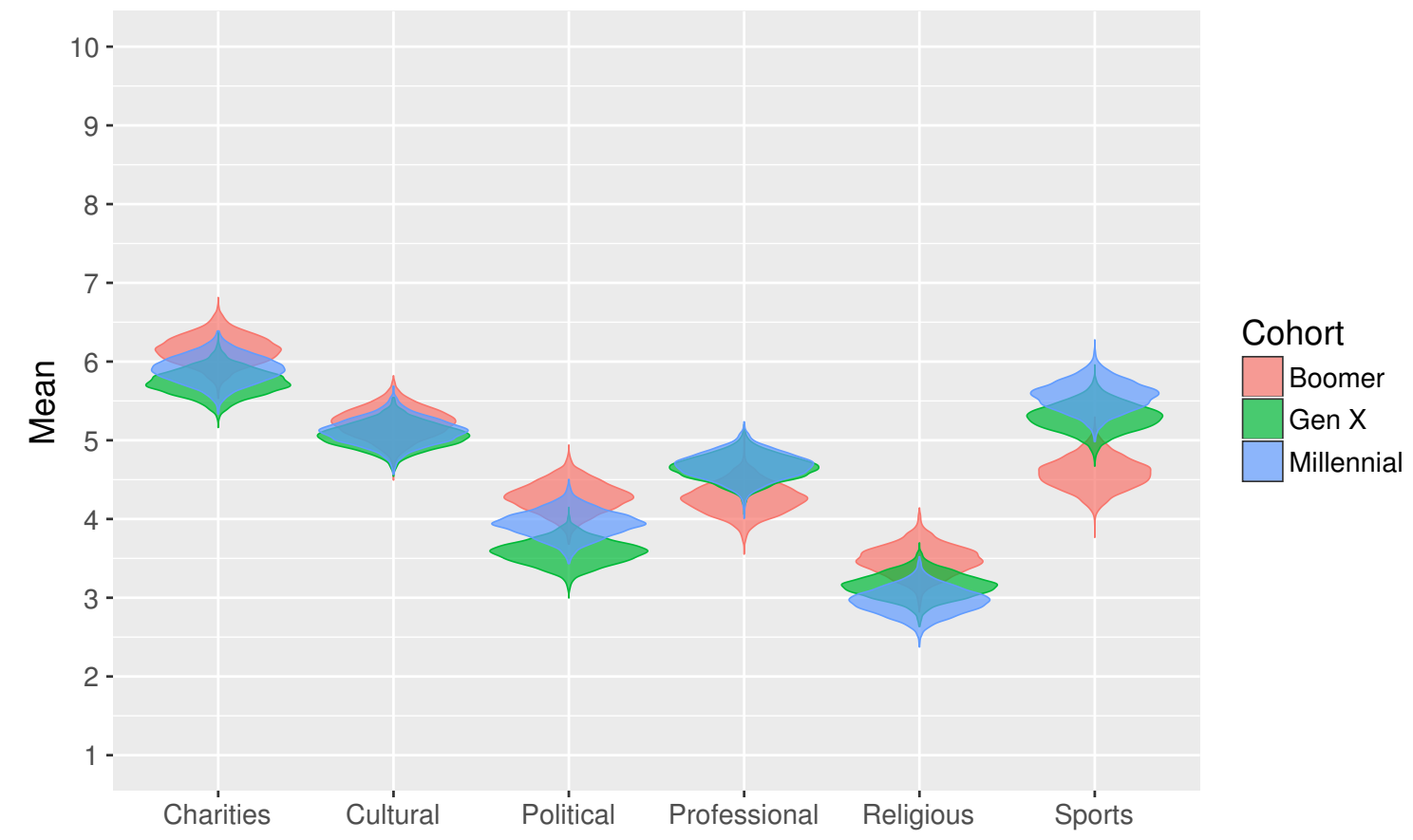

In most cases, the overlap between the posterior distributions for all three cohorts is very large. The greater the overlap, the lower the probability 
that there is an actual difference between the cohorts. There are only two exceptions. The Baby Boomer cohort seems to be somewhat more interested in political NPOs than the Generation X cohort, and the Baby Boomer cohort is somewhat less interested in sports NPOs than both the Generation X and the Millennial cohort.

\subsection{Membership}

The estimation results for general interest in becoming a member are summarized in Figure 2.

Figure 2: Estimation results for interest in becoming a member.

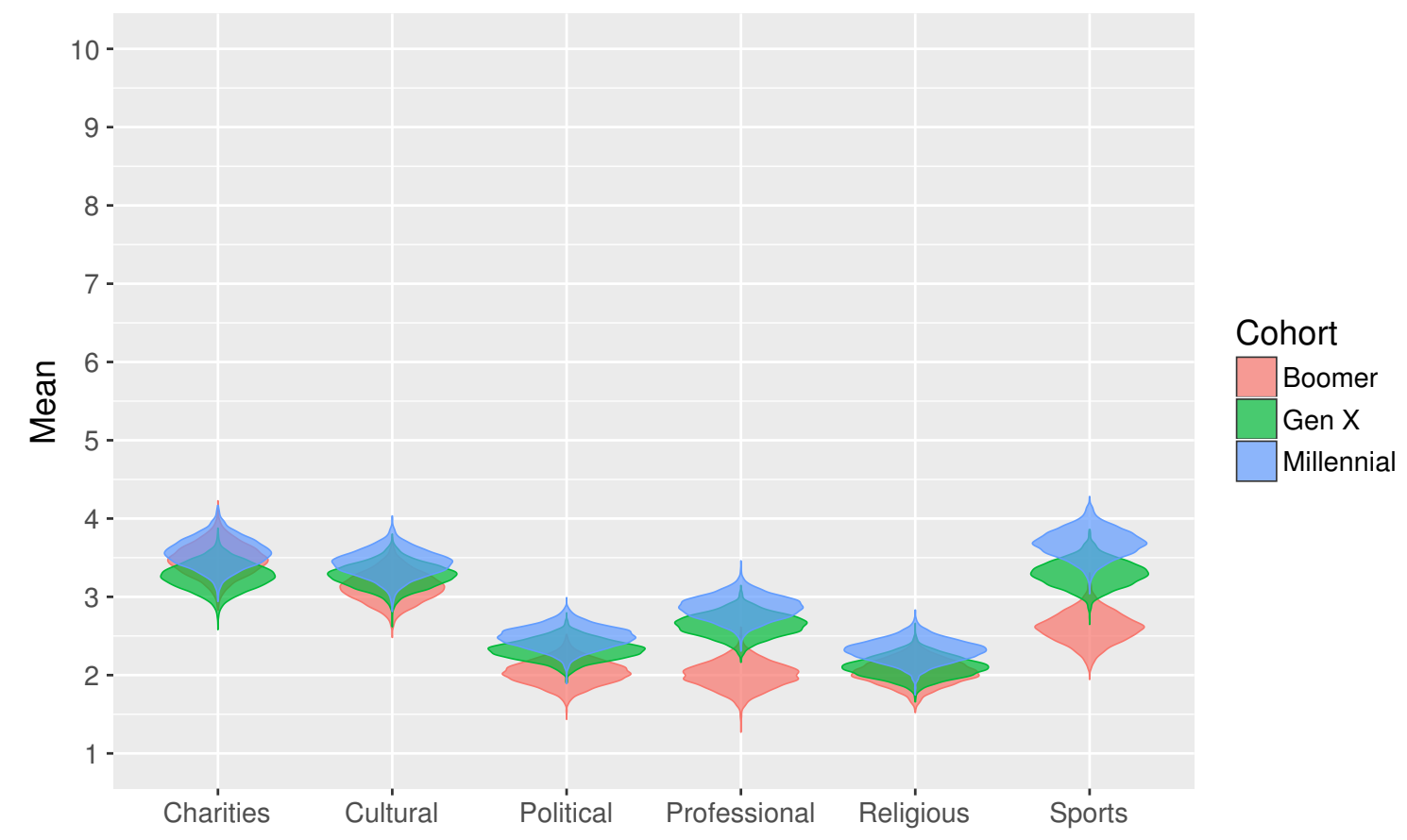

There are, once again, mostly no noticeable differences between the cohorts. But there are, again, two exceptions. Both the Generation X and the Millennial cohorts are somewhat more interested in joining a professional association than the Baby Boomer cohort. Also, there is again a difference with regard to sports NPOs: The Baby Boomer cohort is less interested in joining a sports NPO than the other two cohorts. 


\subsection{Donating}

The estimation results for donation willingness are summarized in Figure 3.

Figure 3: Estimation results for donation willingness.

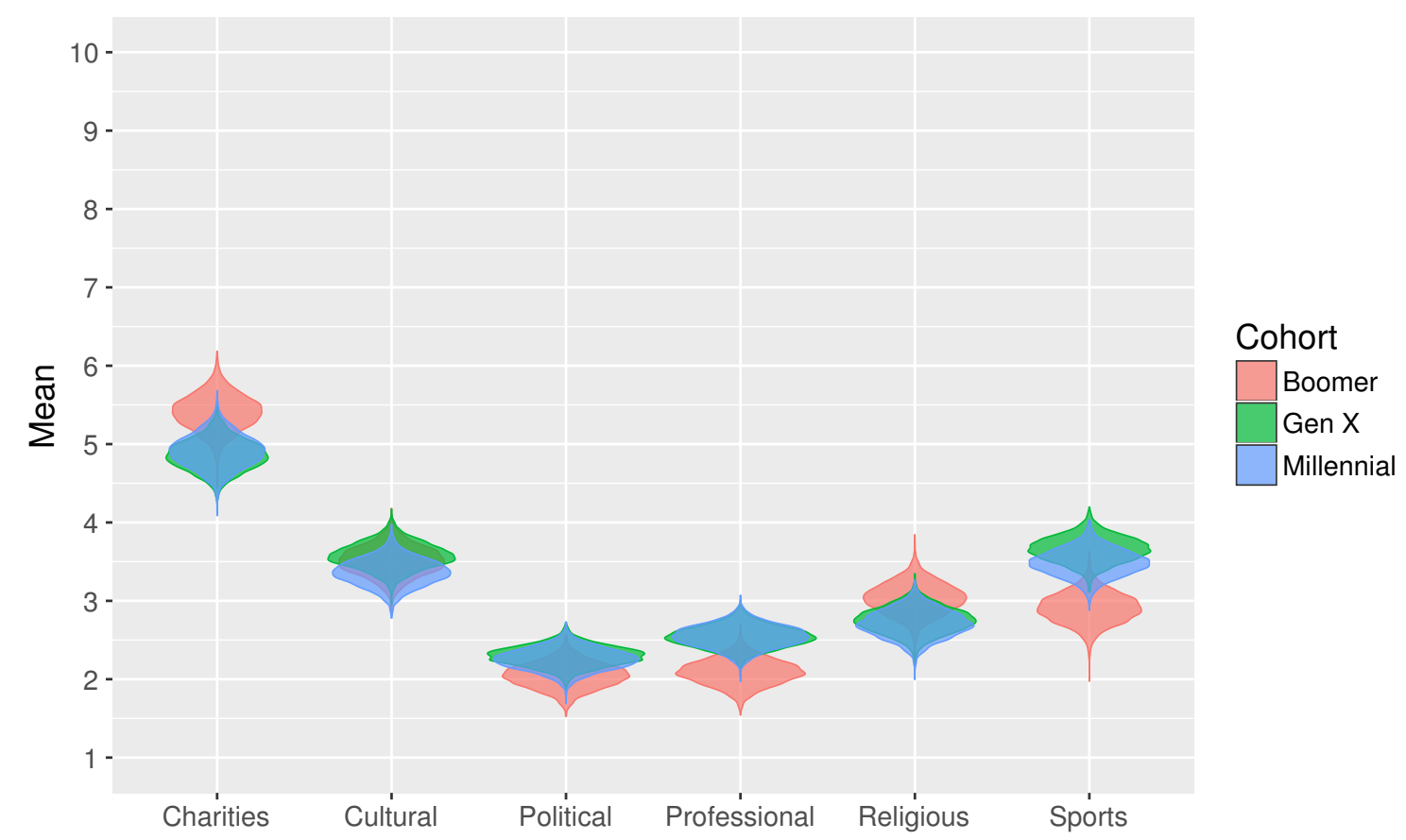

There are, once again, almost no noteworthy differences between the cohorts. The only exception are, once again, sports NPOs: The Baby Boomer cohort is less willing to donate to sports NPOs than the Generation X cohort.

\subsection{Volunteering}

The estimation results for volunteering willingness are summarized in Figure 4.

The results for volunteering willingness resemble the previous ones in that there are only a few noteable differences between the cohorts. The Baby Boomer cohort is less willing to volunteer for professional associations than both the Generation X and the Millennial cohorts. Also, the Baby Boomer cohort is less interested in volunteering for sports NPOs than the other two cohorts.

\subsection{Professional work}

The estimation results for volunteering willingness are summarized in Figure 5. 
Figure 4: Estimation results for volunteering intent.

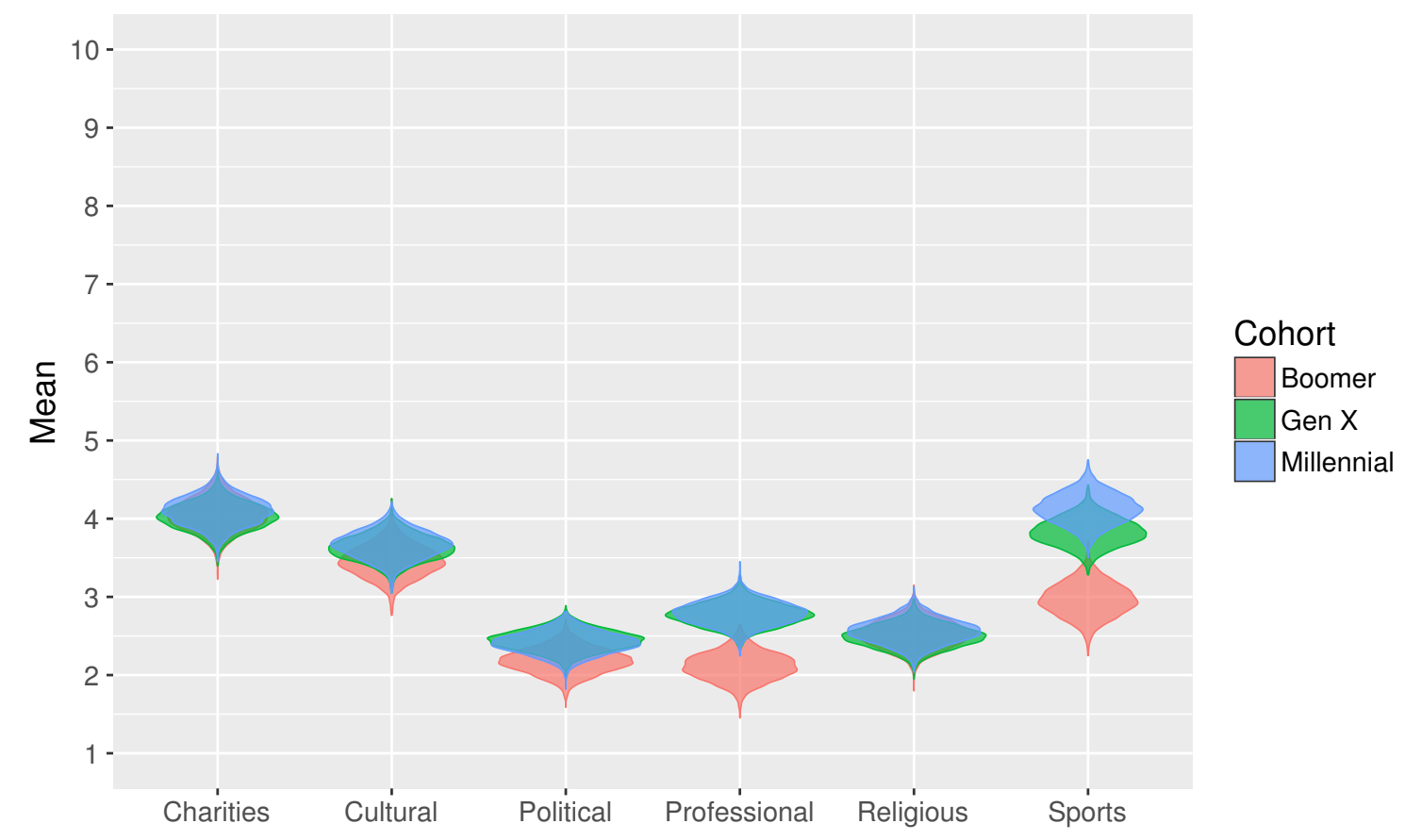

The picture is, once again, very similar to the previous results. There are only two cases of noteable differences. The first are, once again, professional associations: The Baby Boomer cohort is less interested in working professionally for a professional association than both the Generation X and the Millennial cohorts. The second difference is, again, present for sports NPOs: The Baby Boomer cohort is less interested in working for a sports NPO than the other two cohorts.

\subsection{Cluster analysis results}

The results of the cluster analyses are summarized in subsection A.2 in the appendix. The individual cluster analysis results are rather heterogeneous, without any clear pattern emerging. In about half of the cluster analyses, no clusters that resemble generational cohorts emerge. In the other half of the cluster analyses, there are clusters that could be interpreted as being indicative of generational cohorts, but no cluster analysis produced clearcut clusters along the lines of Baby Boomer, Generation X, and Millennial cohorts. The overall result of the cluster analyses can be interpreted as a lack of significant cohort-like grouping structures within the raw data set. 
Figure 5: Estimation results for interest in professional work.

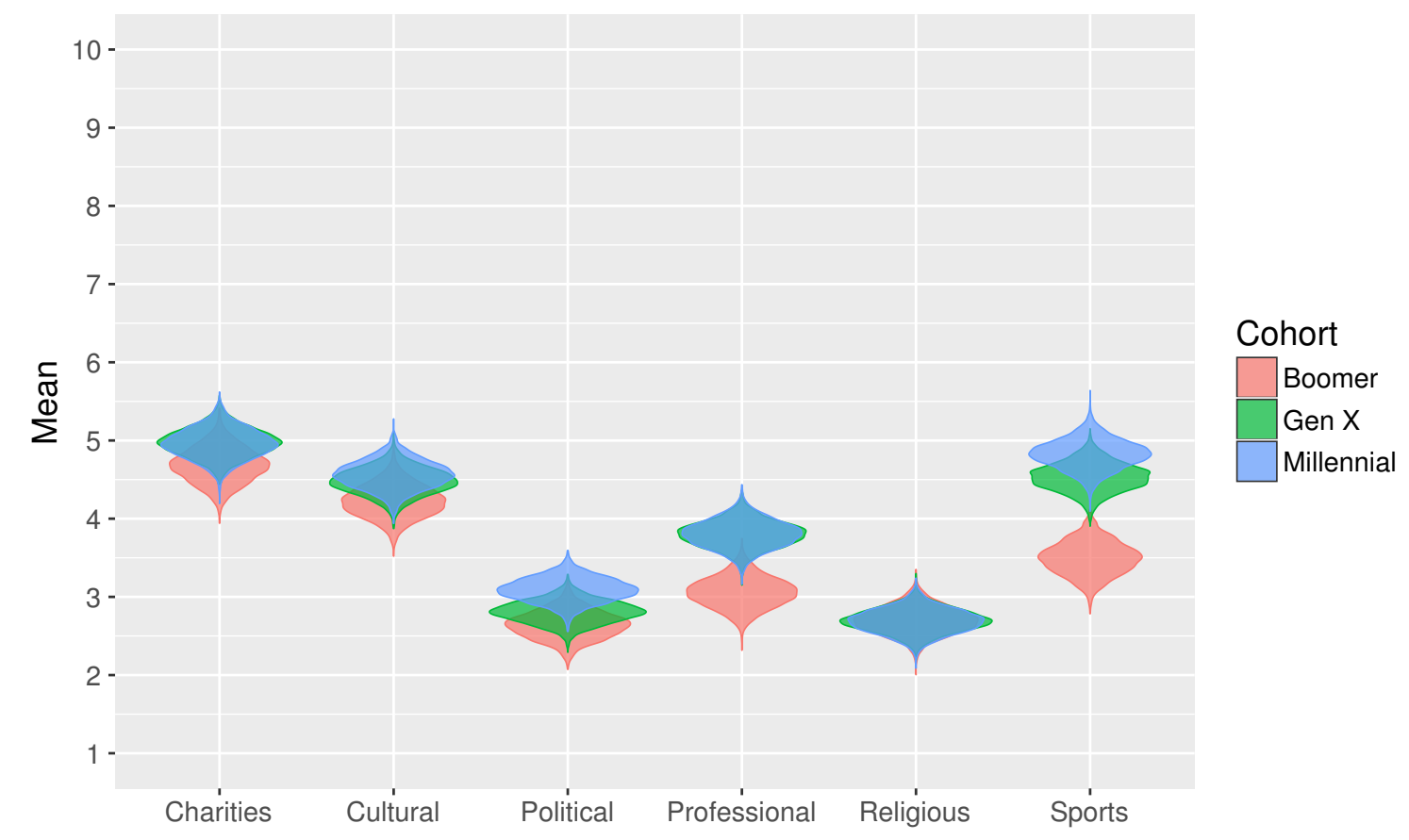

\section{Discussion}

The results of the data analysis suggest four things. First, there are, overall, no strong differences in attitudes towards NPOs between the generational cohorts of Baby Boomers, Generation X, and Millennials. Second, the most pronounced and consistent differences between the generational cohorts can be observed for professional associations and sports NPOs. For both of these NPO types, the Baby Boomer cohort is less willing to volunteer, to join as a member, or to work professionally. In addition, the Baby Boomer cohort is less interested in sports NPOs and less willing to donate to sports NPOs. Third, even in cases where there are differences, the Millennial generational cohort does not stand out; the Millennial cohort is very similar to the Generation X cohort. Fourth, no consistent pattern of generational cohorts emerges when the raw data is submitted to a cluster analysis.

In general, then, the results suggest that there are only few and weak intergenerational differences in attitudes towards NPOs. But what about the findings for professional associations and sports NPOs? Those findings could indicate that there are some few but non-trivial intergenerational differences, but it is also possible that those differences are due to life cycle effects. The 
finding that the Baby Boomer generational cohort exhibits less overall interest in professional associations could be explained by the fact that people in the Baby Boomer cohort are approaching or have already reached retirement age, and the work of professional associations accordingly becomes much less or even entirely irrelevant to them. A similar life cycle effect could be at play with sports NPOs, because active participation in sports tends to decrease with age (Baker et al. 2010, Molanorouzi, Khoo, and Morris 2015).

Overall, the results suggest that there are at most only few and weak intergenerational differences in attitudes towards NPOs.

\section{Conclusions}

Attitudes towards NPOs are caused by a variety of factors. Intergenerational differences, the results of this study suggest, are probably not among them. Even though the absence of notable intergenerational differences means that the present study has produced null results, those null results still contain some useful insights.

Positive attitudes towards NPOs are usually regarded as a proxy for or one dimension of prosocial behavior (Penner et al. 2005). The fact that the Millennial generational cohort does not have noticeably lower or worse attitudes towards NPOs than previous generations could indicate that Millennials are not less prosocial than previous generations. Such a conclusion challenges, to some degree, the finding that narcissism is more pronounced in the Millennial generational cohort (Twenge, Konrath, et al. 2008). Alternatively, the conclusion that the Millennial cohort is at least as prosocial as previous cohorts could mean that greater levels of narcissism do not necessarily causally result in less prosocial behavior because NPOs offer venues for more narcissistic personalities to engage in prosocial behavior, as has been suggested before (Credo et al. 2016).

From the point of view of NPO practitioners, the finding that there are are no noticeable differences in attitudes towards NPOs could be encouraging. If the baseline interest in and willingness to engage with NPOs is no different for the Millennial cohort than it is for previous generational cohorts, then members of the Millennial cohort represent just as much potential for NPOs as previous generational cohorts do. We did not find any evidence that members of the Millennial cohort are less interested in any way in any kind of NPO. From a strategic point of view, one implication for NPO practitioners might therefore be that in order to maximize whatever utility with regard to the Millennial cohort they wish to maximize, it might be beneficial to care about the how more than about the what. Even though there might be few 
or no special traits of the Millennial generational cohort when it comes to attitudes towards NPOs (the what), intergenerational differences in other domains might offer valuable insights for how to engage with the Millennial generational cohort (the how).

\subsection{Limitations of this study}

This study is based on a survey conducted in Switzerland. Since the logic behind the idea of intergenerational differences is that a cohort's shared socio-economic experiences shape values which, in turn, impact more specific attitudes, the question of the generalizability of the results is important.

The Swiss Millennial generational cohort is similar to Millennial cohorts in other Western European and North American countries with regards to a number of contextual factors. For example, Millennials in Switzerland are as much "digital natives" or "digital immigrants" (Prensky 2001) as Millennials in other Western countries. Swiss Millennials enjoy similar levels of education as those in other countries, and they experience similar labour markets, both in terms of how globalized their national economies are (Gygli, Haelg, and Sturm 2018) as well as in terms of changes and trends in the labour market such as the rise of the "gig economy" (Huws et al. 2017).

On the other hand, however, there are also important contextual factors that are different for the Millennial generational cohort in Switzerland compared to other countries. One such factor is student loan debt. In some Western countries, notably the United States (Looney and Yannelis 2015) and, to a lesser degree, the United Kingdom (Marginson 2018), higher education can be a costly endeavor that results in significant volumes student loan debt. In contrast, higher education in Switzerland is comparatively affordable and does not routinely cause great levels of student loan debt. This difference means that the Swiss Millennial generational cohort mostly does not experience the high levels of debt and the corresponding financial pressure during their late adolescence and at the beginning of their professional trajectories that large proportions of Millennial cohorts in other countries do. However, perhaps somewhat counterintuitively, there is some evidence that the Millennial cohort in Switzerland is not particulary optimistic in their socio-political and economic outlook, but actually more pessimistic than Millennial cohorts in other countries (Denk 2018).

In general, the Millennial generational cohort in Switzerland does share some traits with Millennial cohorts in other Western countries (referring to those cohorts with the common expression of "Millennials" is thereby at least partially justified), but it would be imprecise to equate all Millennial cohorts as one single homogeneous group. In addition, and at least as importantly: 
Nonprofit sectors are not identical across countries (Casey 2016). Since the present study is based on a survey conducted in Switzerland, the results are primarily evidence for attitudes towards NPOs in the Swiss context. Accordingly, the results of this study should not be interpreted as entirely reliable pars pro toto evidence on intergenerational differences in attitudes towards NPOs, but rather as a starting point for similar research in other national or comparative settings.

Besides the limited generalizability of the results, a major limitation of the present study is its cross-sectional design. With such a design, it is not possible to untangle intergenerational from life cycle effects. The few differences between the cohorts that our analysis uncovered could, as discussed above, be explained as life cycle effects rather than intergenerational differences.

The limitations of this study suggest directions for future research. Ideally, future research on intergenerational differences in attitudes towards NPOs will implement both longitudinal designs and cross-cultural, international comparisons. But even replicating the present study's cross-sectional design in different national contexts will generate valuable evidence that will gradually offer a more complete picture and allow for for more pre estimate the effect of intergenerational differences on attitudes towards NPOs. 


\section{References}

Anderberg, Michael R. (2014). Cluster Analysis for Applications: Probability and Mathematical Statistics: A Series of Monographs and Textbooks. Academic Press. ISBN: 978-1-4831-9139-3.

Anderson, Janna and Lee Rainie (2012). Millennials will benefit and suffer due to their hyperconnected lives. Tech. rep. Washington DC: Pew Research Center.

Baker, Joseph, Jessica Fraser-Thomas, Rylee A. Dionigi, and Sean Horton (2010). "Sport participation and positive development in older persons". In: European Review of Aging and Physical Activity 7.1, pp. 3-12. DOI: 10.1007/s11556-009-0054-9.

Balabanis, George, Ruth E. Stables, and Hugh C. Phillips (1997). "Market orientation in the top 200 British charity organizations and its impact on their performance". In: European Journal of Marketing 31.8, pp. 583-603. DOI: $10.1108 / 03090569710176592$.

Becker, Penny Edgell and Pawan H. Dhingra (2001). "Religious Involvement and Volunteering: Implications for Civil Society". In: Sociology of Religion 62.3, pp. 315-335. DOI: $10.2307 / 3712353$.

Bekkers, René (2010). "Who gives what and when? A scenario study of intentions to give time and money". In: Social Science Research 39.3, pp. 369-381. DOI: 10.1016/j.ssresearch.2009.08.008.

Bekkers, René and Pamala Wiepking (2011). "Who gives? A literature review of predictors of charitable giving Part One: Religion, education, age and socialisation". In: Voluntary Sector Review 2.3, pp. 337-365. DOI: 10.133 2/204080511X6087712.

Bolton, Ruth N., A. Parasuraman, Ankie Hoefnagels, Nanne Migchels, Sertan Kabadayi, Thorsten Gruber, Yuliya Komarova Loureiro, and David Solnet (2013). "Understanding Generation Y and their use of social media: a review and research agenda". In: Journal of Service Management 24.3, pp. 245-267. DOI: 10.1108/09564231311326987.

Brooks, Arthur C. and James Q. Wilson (2007). Who Really Cares: The Surprising Truth About Compassionate Conservatism. Basic Books. ISBN: 978-0-465-00823-0.

Brown, Eleanor and James M. Ferris (2007). "Social Capital and Philanthropy: An Analysis of the Impact of Social Capital on Individual Giving and Volunteering". In: Nonprofit and Voluntary Sector Quarterly 36.1, pp. 8599. DOI: $10.1177 / 0899764006293178$.

Bürkner, Paul-Christian (2017). "brms: An R Package for Bayesian Multilevel Models Using Stan". In: Journal of Statistical Software 80.1. DOI: 10.186 37/jss.v080.i01. 
Callegaro, Mario, Reg Baker, Jelke Bethlehem, Anja S. Göritz, Jon A. Krosnick, and Paul J. Lavrakas (2014). "Online panel research". In: Online Panel Research. Ed. by Mario Callegaro, Reg Baker, Jelke Bethlehem, Anja S. Göritz, Jon A. Krosnick, and Paul J. Lavrakas. John Wiley \& Sons, Ltd, pp. 1-22. ISBN: 978-1-118-76352-0.

Carpenter, Bob, Andrew Gelman, Matthew Hoffman, Daniel Lee, Ben Goodrich, Michael Betancourt, Marcus Brubaker, Jiqiang Guo, Peter Li, and Allen Riddell (2017). "Stan: A Probabilistic Programming Language". In: Journal of Statistical Software 76.1, pp. 1-32. DOI: 10.18637/jss.v076.i01.

Casey, John (2016). "Comparing Nonprofit Sectors Around the World: What Do We Know and How Do We Know It?" In: Journal of Nonprofit Education and Leadership 6.3. DOI: 10.18666/JNEL-2016-V6-I3-7583.

Credo, Keith R., Patricia A. Lanier, Curtis F. Matherne, and Susie S. Cox (2016). "Narcissism and Entitlement in Millennials: The Mediating Influence of Community Service Self Efficacy on Engagement". In: Personality and Individual Differences 101, pp. 192-195. DOI: $10.1016 / \mathrm{j}$.paid. 2016 .05 .370 .

Deal, Jennifer J., David G. Altman, and Steven G. Rogelberg (2010). "Millennials at Work: What We Know and What We Need to Do (If Anything)". In: Journal of Business and Psychology 25.2, pp. 191-199. DOI: 10.1007 /s10869-010-9177-2.

Denk, Myriam (2018). The Deloitte 2018 Millennial Survey: Switzerland. Tech. rep. Zurich: Deloitte Touche Tohmatsu Limited.

Dolnicar, Sara and Katie Lazarevski (2009). "Marketing in non-profit organizations: an international perspective". In: International Marketing Review 26.3, pp. 275-291. DOI: 10.1108/02651330910960780.

Einolf, Christopher J. and Cheryl Yung (2018). "Super-Volunteers: Who Are They and How Do We Get One?" In: Nonprofit and Voluntary Sector Quarterly, pp. 1-24. DOI: 10.1177/0899764018760400.

Feldmann, Derrick (2016). Social Movements for Good: How Companies and Causes Create Viral Change. Wiley. ISBN: 978-1-119-13339-1.

Feldmann, Derrick, Jonathon Hosea, Melissa Wall, Joey Ponce, and Lara Banker (2015). The 2015 Millennial Impact Report. Tech. rep. West Palm Beach: Achieve.

Fraley, C. and A. E. Raftery (1998). "How Many Clusters? Which Clustering Method? Answers Via Model-Based Cluster Analysis". In: The Computer Journal 41.8, pp. 578-588. DOI: 10.1093/comjnl/41.8.578.

Fraley, Chris, Adrian E. Raftery, Luca Scrucca, Thomas Brendan Murphy, and Michael Fop (2017). mclust: Gaussian Mixture Modelling for Model-Based Clustering, Classification, and Density Estimation. 
Freeman, Richard B. (1997). "Working for Nothing: The Supply of Volunteer Labor". In: Journal of Labor Economics 15.1, Part 2, S140-S166. DOI: 10.1086/209859.

García-Mainar, Inmaculada and Carmen Marcuello (2007). "Members, Volunteers, and Donors in Nonprofit Organizations in Spain". In: Nonprofit and Voluntary Sector Quarterly 36.1, pp. 100-120. DOI: 10.1177/0899764006 293179 .

Gelman, Andrew, John B. Carlin, Hal S. Stern, David B. Dunson, Aki Vehtari, and Donald B. Rubin (2013). Bayesian Data Analysis. Boca Raton: Taylor \& Francis Ltd. ISBN: 978-1-4398-4095-5.

Gelman, Andrew and Eric Loken (2013). "The garden of forking paths: Why multiple comparisons can be a problem, even when there is no "fishing expedition" or "p-hacking" and the research hypothesis was posited ahead of time". In: Department of Statistics, Columbia University.

Gelman, Andrew and Donald B. Rubin (1992). "Inference from Iterative Simulation Using Multiple Sequences". In: Statistical Science 7.4, pp. 457472. DOI: $10.1214 / \mathrm{ss} / 1177011136$.

Gorczyca, Matthew and Rosanne L. Hartman (2017). "The New Face of Philanthropy: The Role of Intrinsic Motivation in Millennials' Attitudes and Intent to Donate to Charitable Organizations". In: Journal of Nonprofit Es Public Sector Marketing 29.4, pp. 415-433. DOI: 10.1080/10495142.2 017.1326349 .

Gui, Benedetto (1991). "The Economic Rationale for the "third Sector"". In: Annals of Public and Cooperative Economics 62.4, pp. 551-572. DOI: 10.1111/j.1467-8292.1991.tb01367.x.

Gygli, Savina, Florian Haelg, and Jan-Egbert Sturm (2018). The KOF Globalisation Index - Revisited. Working Paper. KOF Swiss Economic Institute, ETH Zurich. DOI: $10.3929 /$ ethz-b-000238666.

Hager, Mark A., Joseph Galaskiewicz, and Jeff A. Larson (2004). "Structural embeddedness and the liability of newness among nonprofit organizations". In: Public Management Review 6.2, pp. 159-188. DOI: 10.1080/1471903 042000189083 .

Hannan, Michael T. and John Freeman (1977). "The Population Ecology of Organizations". In: American Journal of Sociology 82.5, pp. 929-964. DOI: 10.1086/226424.

Helmig, Bernd, Marc Jegers, and Irvine Lapsley (2004). "Challenges in Managing Nonprofit Organizations: A Research Overview". In: Voluntas: International Journal of Voluntary and Nonprofit Organizations 15.2, pp. 101-116. DOI: 10.1023/B:VOLU.0000033176.34018.75. 
Helms, Sara E. and Jeremy P. Thornton (2012). "The influence of religiosity on charitable behavior: A COPPS investigation". In: The Journal of SocioEconomics 41.4, pp. 373-383. DOI: $10.1016 / \mathrm{j}$.socec.2012.04.003.

Hitlin, Steven and Jane Allyn Piliavin (2004). "Values: Reviving a Dormant Concept". In: Annual Review of Sociology 30.1, pp. 359-393. DOI: 10.114 6/annurev.soc.30.012703.110640.

Howe, Neil and William Strauss (2009). Millennials Rising: The Next Great Generation. Knopf Doubleday Publishing Group. ISBN: 978-0-307-55794-0.

Huws, Ursula, Neil H Spencer, Dag S Syrdal, and Kaire Holts (2017). Work in the European gig economy: research results from the UK, Sweden, Germany, Austria, The Netherlands, Switzerland and Italy. Brussels: Foundation for European Progressive Studies. ISBN: 978-2-930769-11-0.

Inglehart, Ronald and Christian Welzel (2010). "Changing Mass Priorities: The Link between Modernization and Democracy". In: Perspectives on Politics 8.02, pp. 551-567. DOI: 10.1017/S1537592710001258.

Katherine Taken Smith (2012). "Longitudinal study of digital marketing strategies targeting Millennials". In: Journal of Consumer Marketing 29.2, pp. 86-92. DOI: 10.1108/07363761211206339.

Kramer, Ralph M. (2000). "A Third Sector in the Third Millennium?" In: Voluntas: International Journal of Voluntary and Nonprofit Organizations 11.1, pp. 1-23. DOI: 10.1023/A:1008914531485.

Kucera, Jacqueline and Athena Krummenacher (2017). Switzerland's population 2016. 1155-1600. Neuchâtel: Federal Statistical Office FSO.

Lambert, T. Allen (1972). "Generations and Change: Toward a Theory of Generations as a Force in Historical Process". In: Youth 85 Society 4.1, pp. 21-45. DOI: 10.1177/0044118X7200400103.

Lecy, Jesse D., Hans Peter Schmitz, and Haley Swedlund (2012). "NonGovernmental and Not-for-Profit Organizational Effectiveness: A Modern Synthesis". In: VOLUNTAS: International Journal of Voluntary and Nonprofit Organizations 23.2, pp. 434-457. DOI: 10.1007/s11266-011-92046.

Lee, Yu-Kang and Chun-Tuan Chang (2007). "Who gives what to charity? Characteristics affecting donation behavior". In: Social Behavior and Personality: an international journal 35.9, pp. 1173-1180. DOI: 10.2224 /sbp.2007.35.9.1173

Leete, Laura (2006). "Work in the nonprofit sector". In: The Nonprofit Sector: A Research Handbook, Second Edition. Ed. by Walter W. Powell and Richard Steinberg. Yale University Press, pp. 159-179. ISBN: 978-0-30010903-0.

Looney, Adam and Constantine Yannelis (2015). A crisis in student loans? How changes in the characteristics of borrowers and in the institutions 
they attended contributed to rising loan defaults. Brookings Papers on Economic Activity. Washington, D.C.: Brookings.

Maier, Florentine, Michael Meyer, and Martin Steinbereithner (2016). "Nonprofit Organizations Becoming Business-Like: A Systematic Review". In: Nonprofit and Voluntary Sector Quarterly 45.1, pp. 64-86. DOI: 10.1177 10899764014561796.

Mannheim, Karl (1952). "The Problem of Generations". In: Essays on the Sociology of Knowledge. Ed. by Paul Kecskemeti and Karl Mannheim. Routledge \& Kegan Paul, pp. 276-332.

Marginson, Simon (2018). "Global trends in higher education financing: The United Kingdom". In: International Journal of Educational Development. Global Trends in Higher Education Financing 58, pp. 26-36. DOI: 10.101 6/j.ijedudev.2017.03.008.

Margolis, Michele F. and Michael W. Sances (2017). "Partisan Differences in Nonpartisan Activity: The Case of Charitable Giving". In: Political Behavior 39.4, pp. 839-864. DOI: 10.1007/s11109-016-9382-4.

Maslow, Abraham H. (1943). "A theory of human motivation". In: Psychological Review 50.4, pp. 370-396. DOI: 10.1037/h0054346.

Mendoza-Abarca, Karla I. and David Gras (2017). "The Performance Effects of Pursuing a Diversification Strategy by Newly Founded Nonprofit Organizations". In: Journal of Management, p. 0149206316685854. DOI: 10.1177/0149206316685854.

Molanorouzi, Keyvan, Selina Khoo, and Tony Morris (2015). "Motives for adult participation in physical activity: type of activity, age, and gender". In: BMC Public Health 15. DOI: 10.1186/s12889-015-1429-7.

Ng, Eddy S. W., Linda Schweitzer, and Sean T. Lyons (2010). "New Generation, Great Expectations: A Field Study of the Millennial Generation". In: Journal of Business and Psychology 25.2, pp. 281-292. DOI: 10.1007/s10 869-010-9159-4.

Nisbett, Gwendelyn S. and Marianna Strzelecka (2017). "Appealing to Goodwill or YOLO-Promoting Conservation Volunteering to Millennials". In: VOLUNTAS: International Journal of Voluntary and Nonprofit Organizations 28.1, pp. 288-306. DOI: 10.1007/s11266-016-9815-z.

Norris, Pippa and Ronald Inglehart (2011). Sacred and Secular: Religion and Politics Worldwide. Cambridge University Press. ISBN: 978-1-139-49966-8.

Onyx, Jenny and Madi Maclean (1996). "Careers in the third sector". In: Nonprofit Management and Leadership 6.4, pp. 331-345. DOI: 10.1002 $/ \mathrm{nml} .4130060404$.

Parry, Emma and Peter Urwin (2011). "Generational Differences in Work Values: A Review of Theory and Evidence". In: International Journal of 
Management Reviews 13.1, pp. 79-96. DOI: $10.1111 / \mathrm{j} .1468-2370.2010$ $.00285 . \mathrm{x}$.

Penner, Louis A., John F. Dovidio, Jane A. Piliavin, and David A. Schroeder (2005). "Prosocial Behavior: Multilevel Perspectives". In: Annual Review of Psychology 56.1, pp. 365-392. DOI: 10.1146/annurev.psych.56.0911 03.070141 .

Piper, Greg and Sylke V Schnepf (2007). Gender Differences in Charitable Giving. Discussion Paper 3242. Bonn: Institute for the Study of Labor, p. 32.

Polson, Nicholas G. and James G. Scott (2012). "On the Half-Cauchy Prior for a Global Scale Parameter". In: Bayesian Analysis 7.4, pp. 887-902. DOI: $10.1214 / 12-B A 730$.

Prensky, Marc (2001). "Digital Natives, Digital Immigrants Part 1". In: On the Horizon 9.5, pp. 1-6. DOI: 10.1108/10748120110424816.

R Core Team (2015). R: A Language and Environment for Statistical Computing. Vienna, Austria.

Rose-Ackerman, Susan (1996). "Altruism, Nonprofits, and Economic Theory". In: Journal of Economic Literature 34.2, pp. 701-728.

Roshwalb, Alan, Neale El-Dash, and Clifford Young (2016). Towards the Use of Bayesian Credibility Intervals in Online Survey Results. Tech. rep. Ipsos Public Affairs.

Salamon, Lester M and Helmut K Anheier (1996). The international classification of nonprofit organizations: ICNPO-Revision 1, 1996. Johns Hopkins University Institute for Policy Studies.

Salamon, Lester M. and Helmut K. Anheier (1997). Defining the Nonprofit Sector: A Cross-national Analysis. Manchester University Press. ISBN: 978-0-7190-4902-6.

Saratovsky, Kari Dunn, Derrick Feldmann, and Jean Case (2013). Cause for Change: The Why and How of Nonprofit Millennial Engagement. JosseyBass. ISBN: 978-1-118-34826-0.

Schwarz, Gideon (1978). "Estimating the Dimension of a Model". In: The Annals of Statistics 6.2, pp. 461-464. DOI: 10.1214/aos/1176344136.

Seemiller, Corey and Meghan Grace (2016). Generation Z Goes to College. John Wiley \& Sons. ISBN: 978-1-119-14345-1.

Simmons, Joseph P., Leif D. Nelson, and Uri Simonsohn (2011). "False-Positive Psychology: Undisclosed Flexibility in Data Collection and Analysis Allows Presenting Anything as Significant". In: Psychological Science 22.11, pp. 1359-1366. DOI: $10.1177 / 0956797611417632$.

Smith, Natalie L., Adam Cohen, and Andrew C. Pickett (2014). "Exploring the motivations and outcomes of long-term international sport-for-development 
volunteering for American Millennials". In: Journal of Sport \& Tourism 19.3-4, pp. 299-316. DOI: 10.1080/14775085.2016.1143865.

Steinberg, Richard (2003). "Economic Theories of Nonprofit Organizations". In: The Study of the Nonprofit Enterprise. Nonprofit and Civil Society Studies. Springer, Boston, MA, pp. 277-309. ISBN: 978-0-306-47855-0. DOI: 10.1007/978-1-4615-0131-2_16.

Taylor, Paul, Kim Parker, Rich Morin, Eileen Patten, and Anna Brown (2014). Millennials in Adulthood: Detached from Institutions, Networked with Friends. Tech. rep. Pew Research Center.

Tchirhart, Mary (2006). "Nonprofit Membership Associations". In: The Nonprofit Sector: A Research Handbook, Second Edition. Ed. by Walter W. Powell and Richard Steinberg. Yale University Press, pp. 523-541. ISBN: 978-0-300-10903-0.

Teune, Henry and Adam Przeworski (1970). "The Logic of Comparative Social Inquiry". In: New York.

Tkalac Verčič, Ana and Dejan Verčič (2013). "Digital natives and social media". In: Public Relations Review 39.5, pp. 600-602. DOI: 10.1016/j.pubrev.2 013.08 .008 .

Turner, Anthony (2015). "Generation Z: Technology and Social Interest". In: The Journal of Individual Psychology 71.2, pp. 103-113. DOI: 10.1353 /jip.2015.0021.

Twenge, Jean M. and Stacy M. Campbell (2012). "Who are the Millennials? Empirical evidence for generational differences in work values, attitudes and personality". In: Managing the New Workforce. Ed. by Eddy Ng, Sean Lyons, and Linda Schweitzer. Edward Elgar Publishing, pp. 1-19. ISBN: 978-0-85793-301-0.

Twenge, Jean M., Sara Konrath, Joshua D. Foster, W. Keith Campbell, and Brad J. Bushman (2008). "Egos Inflating Over Time: A Cross-Temporal Meta-Analysis of the Narcissistic Personality Inventory". In: Journal of Personality 76.4, pp. 875-902. DOI: 10.1111/j.1467-6494.2008.00507 . $\mathrm{X}$.

Wang, Lili and Elizabeth Graddy (2008). "Social Capital, Volunteering, and Charitable Giving". In: VOLUNTAS: International Journal of Voluntary and Nonprofit Organizations 19.1, p. 23. DOI: 10.1007/s11266-008-905 $5-\mathrm{y}$.

Welzel, Christian and Ronald Inglehart (2010). "Agency, Values, and WellBeing: A Human Development Model". In: Social Indicators Research 97.1, pp. 43-63. DOI: $10.1007 / \mathrm{s} 11205-009-9557-z$.

Westall, Andrea (2009). Economic analysis and the third sector: Overview of economic analysis in relation to the third sector. Working Paper 14. Birmingham: Third Sector Research Centre. 
Wiepking, Pamala and René Bekkers (2012). "Who gives? A literature review of predictors of charitable giving. Part Two: Gender, family composition and income". In: Voluntary Sector Review 3.2, pp. 217-245. DOI: 10.1332 /204080512X649379.

Wilson, John (2012). "Volunteerism Research: A Review Essay". In: Nonprofit and Voluntary Sector Quarterly 41.2, pp. 176-212. DOI: 10.1177/089976 4011434558 .

Young, Amy M. and Mary D. Hinesly (2012). "Identifying Millennials' key influencers from early childhood: insights into current consumer preferences". In: Journal of Consumer Marketing 29.2, pp. 146-155. DOI: $10.1108 / 07363761211206393$.

Zhang, Li-Chun (2000). "Post-Stratification and Calibration-A Synthesis". In: The American Statistician 54.3, pp. 178-184. DOI: 10.2307/2685587. 


\section{A Appendix}

\section{A.1 Descriptive information}

The descriptive summary of the data set is presented in Table 2 and Table 3 (The descriptive information is divided into two tables for the purpose of legibility.).

Table 2: Descriptive information, part 1: General interest, membership, and donating.

\begin{tabular}{|c|c|c|c|c|c|c|c|c|c|}
\hline & \multicolumn{3}{|c|}{ General interest } & \multicolumn{3}{|c|}{ Membership } & \multicolumn{3}{|c|}{ Donating } \\
\hline & mean & median & $S D$ & mean & median & $S D$ & mean & median & $S D$ \\
\hline Charities & 5.90 & 6 & 2.59 & 3.42 & 2 & 2.82 & 5.03 & 5 & 3.25 \\
\hline Cultural & 5.12 & 5 & 2.56 & 3.28 & 2 & 2.60 & 3.49 & 3 & 2.67 \\
\hline Political & 3.88 & 4 & 2.53 & 2.30 & 1 & 2.10 & 2.21 & 1 & 2.16 \\
\hline Professional & 4.55 & 5 & 2.67 & 2.54 & 1 & 2.39 & 2.42 & 1 & 2.28 \\
\hline Religious & 3.18 & 2 & 2.58 & 2.16 & 1 & 2.18 & 2.81 & 1 & 2.79 \\
\hline Sports & 5.19 & 5 & 2.86 & 3.24 & 2 & 2.76 & 3.39 & 2 & 2.73 \\
\hline
\end{tabular}

Table 3: Descriptive information, part 2: Volunteering and professional work.

\begin{tabular}{|c|c|c|c|c|c|c|}
\hline & \multicolumn{3}{|c|}{ Volunteering } & \multicolumn{3}{|c|}{ Professional work } \\
\hline & mean & median & $S D$ & mean & median & $S D$ \\
\hline Charities & 4.05 & 3 & 2.96 & 4.88 & 5 & 3.04 \\
\hline Cultural & 3.59 & 3 & 2.78 & 4.44 & 4 & 2.90 \\
\hline Political & 2.36 & 1 & 2.21 & 2.86 & 1 & 2.45 \\
\hline Professional & 2.60 & 1 & 2.48 & 3.60 & 3 & 2.82 \\
\hline Religious & 2.52 & 1 & 2.48 & 2.70 & 1 & 2.47 \\
\hline Sports & 3.69 & 3 & 2.98 & 4.35 & 4 & 3.03 \\
\hline
\end{tabular}




\section{A.2 Cluster analyses}

The results of the cluster analyses is summarized in Figure 6 to Figure 10 . The different colors represent different clusters, and the opacity of individual points (respondents) is a visual representation of the probability that that point belongs to the cluster it was assigned to. For the purpose of visual legibility, a slight random jitter was added to the scatterplots (The jitter reduced overlap of points.).

Figure 6: Cluster results for general interest in NPOs.
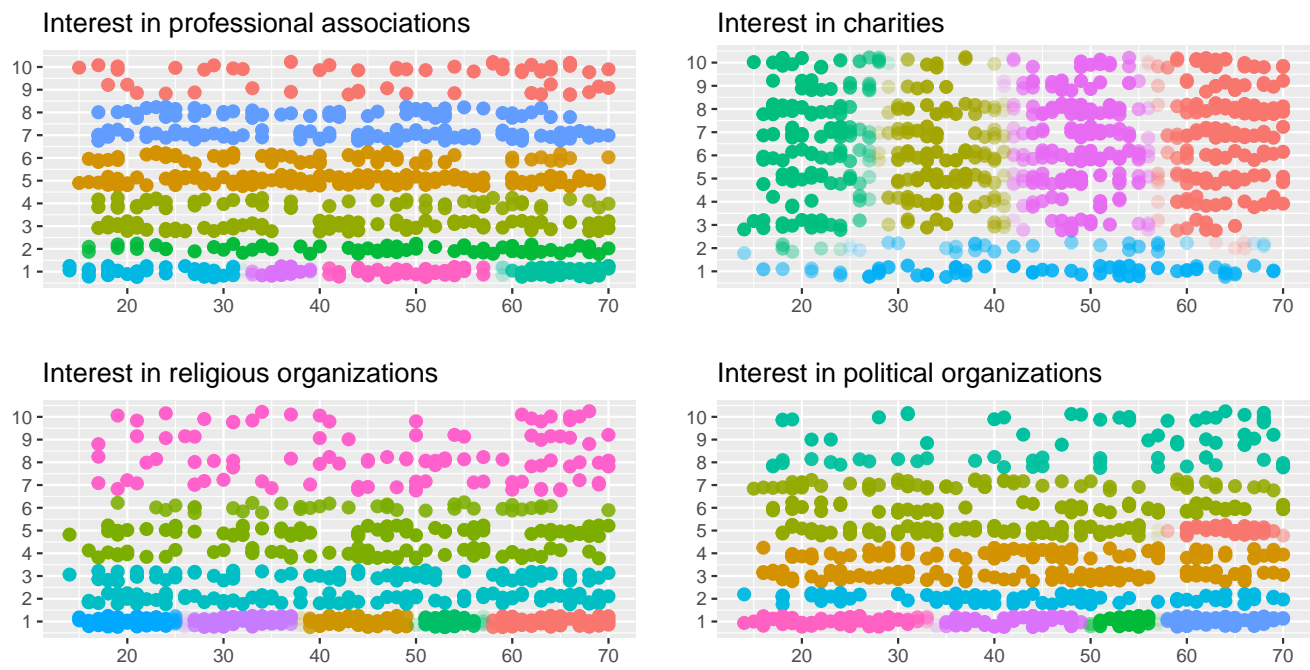

Interest in political organizations

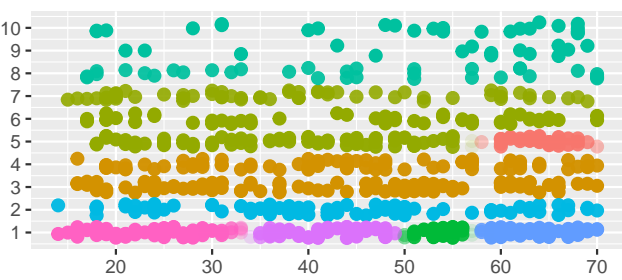

Interest in cultural organizations
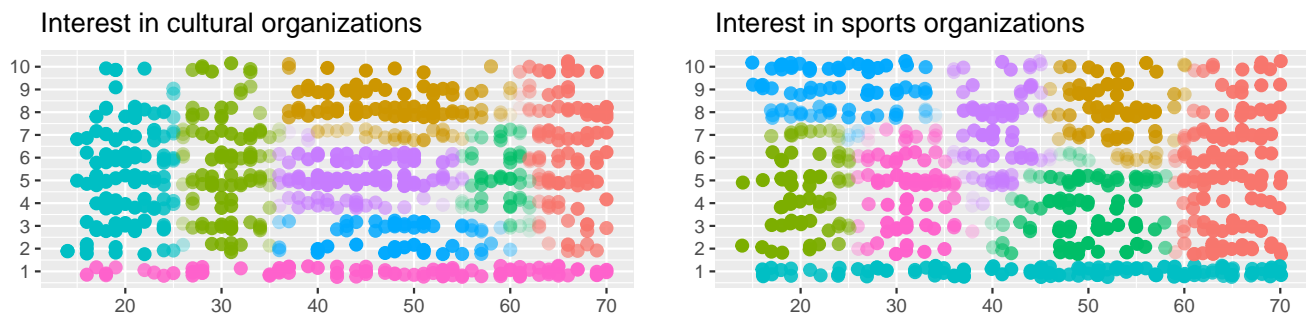

Note: The $x$-axis is age, and the $y$-axis is the level of general interest. 
Figure 7: Cluster results for interest in becoming a member.
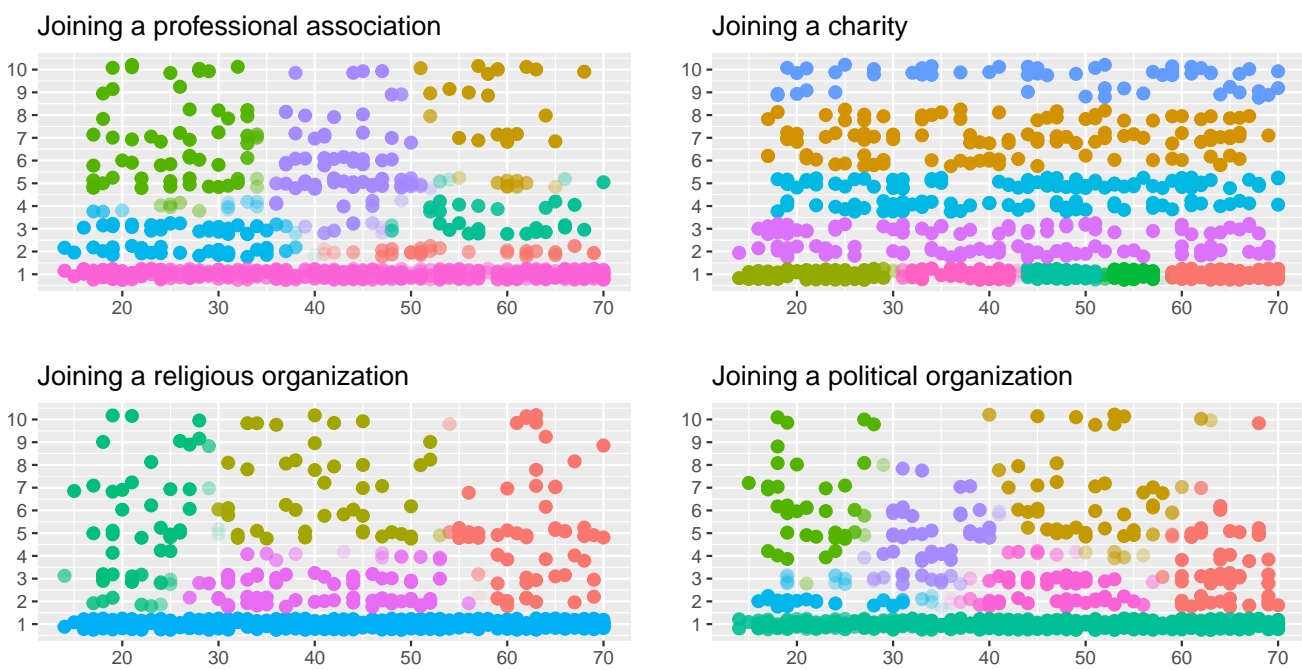

\section{Joining a political organization}

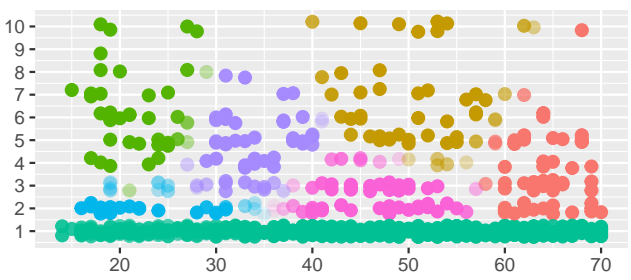

Joining a sports organization

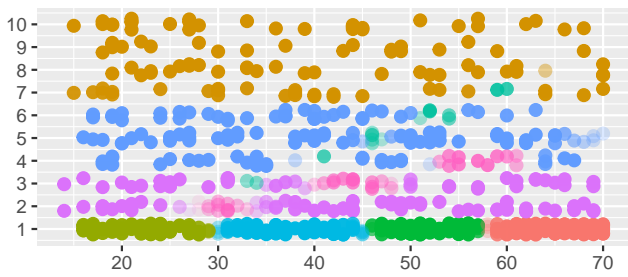

Note: The $x$-axis is age, and the $y$-axis is the level of interest in becoming a member. 
Figure 8: Cluster results for donation willingness.

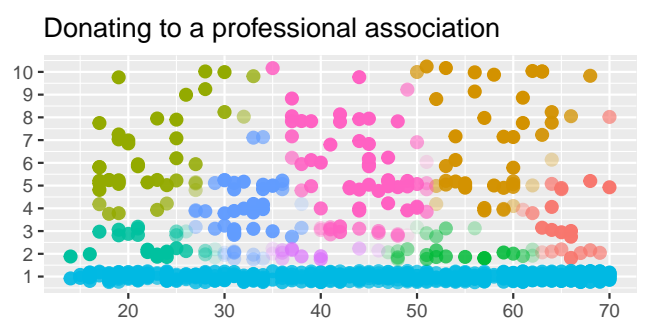

$$
\text { Donating to a charity }
$$

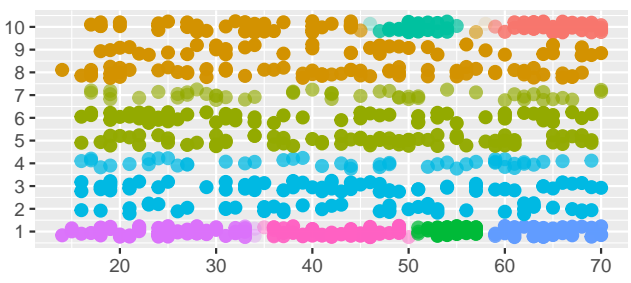

Donating to a religious organization

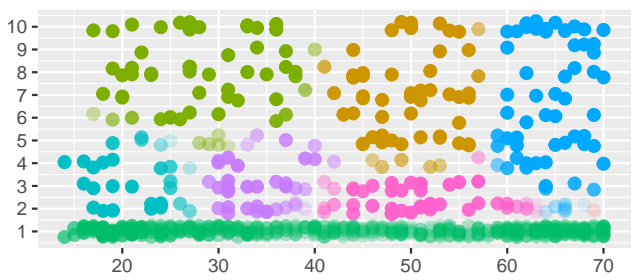

Donating to a political organization

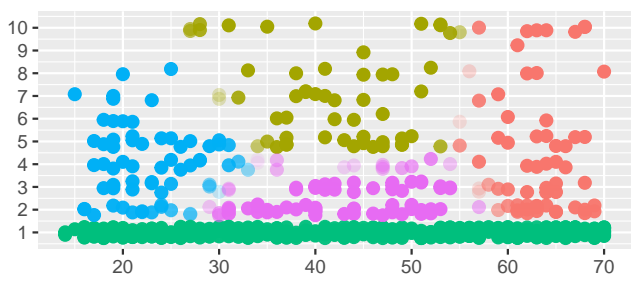

Donating to a cultural organization

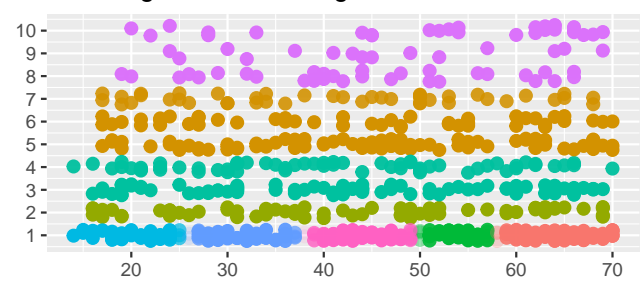

Donating to a sports organization

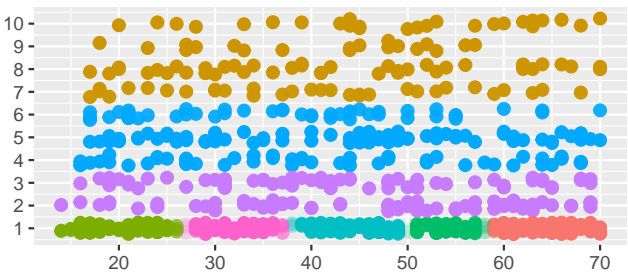

Note: The $x$-axis is age, and the y-axis is the willingness to donate. 
Figure 9: Cluster results for volunteering willingness.

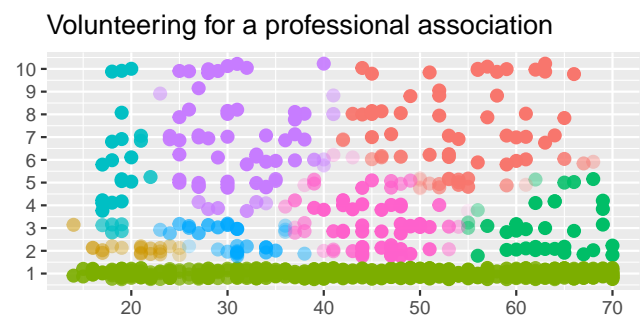

Volunteering for a charity

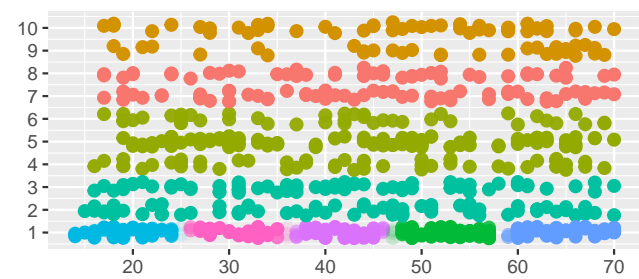

Volunteering for a religious organization

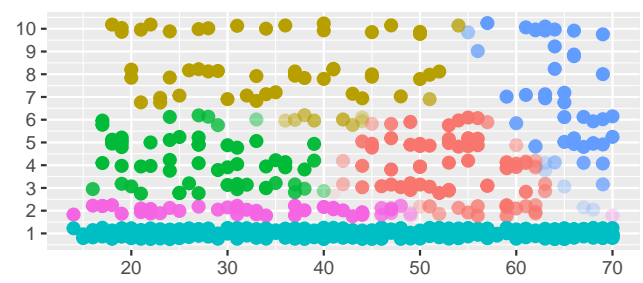

Volunteering for a political organization

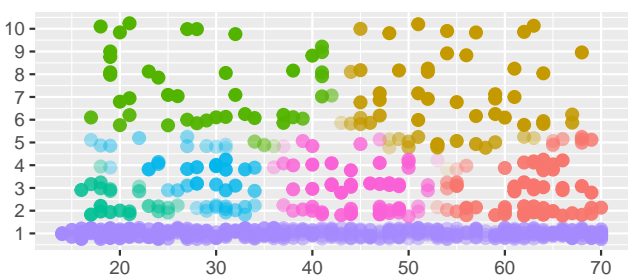

Volunteering for a cultural organization

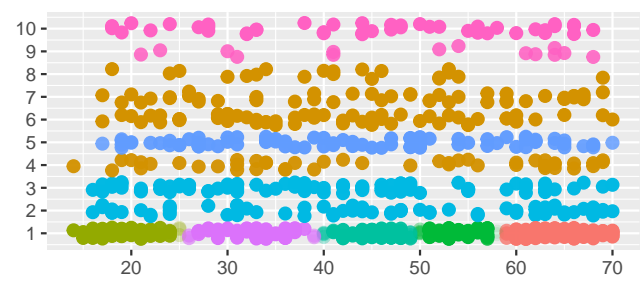

Volunteering for a sports organization

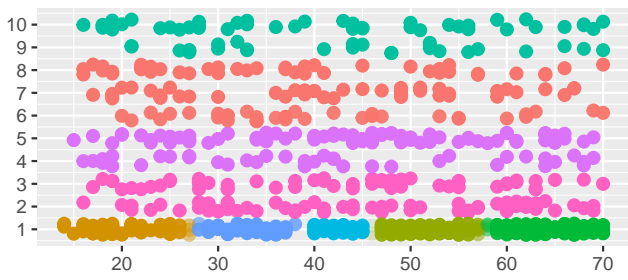

Note: The $x$-axis is age, and the y-axis is the willingness to volunteer. 
Figure 10: Cluster results for interest in professional work.
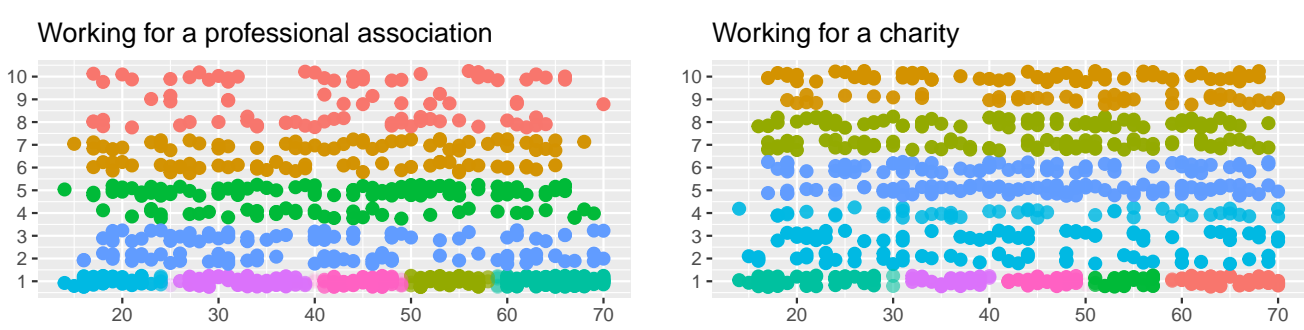

Working for a religious organization

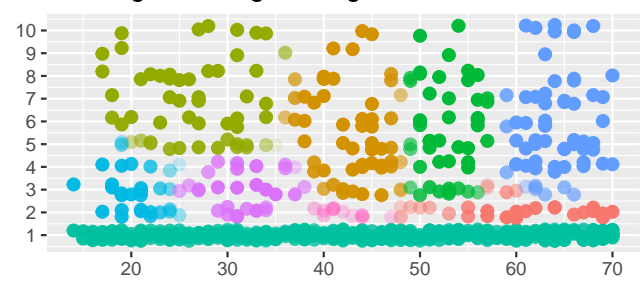

Working for a political organization
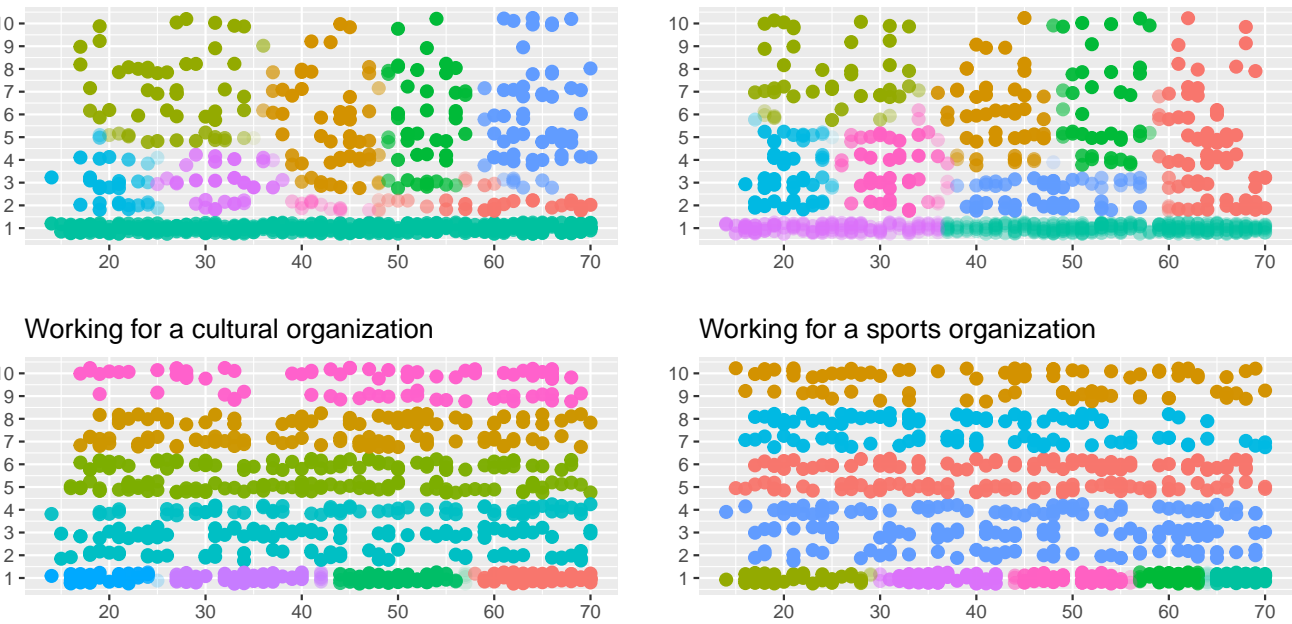

Working for a sports organization

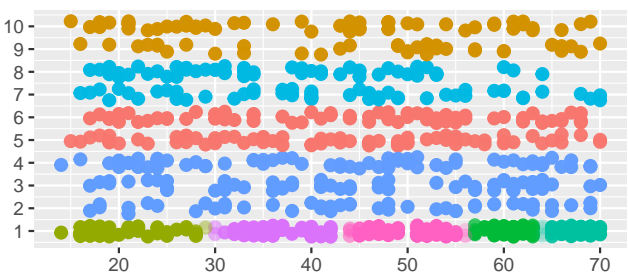

Note: The $x$-axis is age, and the y-axis is the level of interest in working professionally for an NPO. 